\title{
A State-wide Health IT Infrastructure for Population Health: Building a Community-wide Electronic Platform for Maryland's All-Payer Global Budget
}

\author{
Elham Hatef ${ }^{1}$, Hadi Kharrazi ${ }^{1}$, Ed VanBaak ${ }^{2}$, Marc Falcone ${ }^{2}$, Lindsey Ferris ${ }^{2}$, Kory Mertz ${ }^{2}$, Chad \\ Perman $^{3}$, Alice Bauman ${ }^{3}$, Elyse C Lasser ${ }^{1}$, Jonathan P. Weiner ${ }^{1}$
}

1. Center for Population Health IT, Department of Health Policy and Management, Johns Hopkins Bloomberg School of Public Health, Baltimore, MD

2. Chesapeake Regional Information System for our Patients (CRISP), Columbia, Maryland

3. Office of Population Health Improvement, Maryland Department of Health, Baltimore, MD

\begin{abstract}
Maryland Department of Health (MDH) has been preparing for alignment of its population health initiatives with Maryland's unique All-Payer hospital global budget program. In order to operationalize population health initiatives, it is required to identify a starter set of measures addressing community level health interventions and to collect interoperable data for those measures. The broad adoption of electronic health records (EHRs) with ongoing data collection on almost all patients in the state, combined with hospital participation in health information exchange (HIE) initiatives, provides an unprecedented opportunity for near real-time assessment of the health of the communities. MDH's EHR-based monitoring complements, and perhaps replaces, ad-hoc assessments based on limited surveys, billing, and other administrative data. This article explores the potential expansion of health IT capacity as a method to improve population health across Maryland.

First, we propose a progression plan for four selected community-wide population health measures: body mass index, blood pressure, smoking status, and falls-related injuries. We then present an assessment of the current and near real-time availability of digital data in Maryland including the geographic granularity on which each measure can be assessed statewide. Finally, we provide general recommendations to improve interoperable data collection for selected measures over time via the Maryland HIE. This paper is intended to serve as a highlevel guiding framework for communities across the US that are undergoing healthcare transformation toward integrated models of care using universal interoperable EHRs.
\end{abstract}

Keywords: Population Health Measures, Maryland All-Payer Model, Health Information Exchange, Electronic Health Record

Abbreviations: Admission-Discharge-Transfer (ADT) Systems, Alternative Payment Models (APM), Behavioral Risk Factor Surveillance System (BRFSS), Blood Pressure (BP), Body Mass Index (BMI), Centers for Medicare and Medicaid Services (CMS), Chesapeake Regional Information System for our Patients (CRISP), Clinical Quality Measure (CQM) Aligned Population Health Reporting Tool (CAliPHR tool), Consolidated Clinical Document Architecture (C-CDA), Electronic Health Records (EHRs), Emergency Department (ED), Fast Healthcare Interoperability Resources (FHIR), Follow up (f/u), Health Information Exchange (HIE), Health Services Cost Review Commission (HSCRC), Maryland Department of Health (MDH), Maryland Medical Care Data Base (MCDB), Maryland State Health Improvement Process (SHIP), Merit-Based Incentive Program (MIPS), National Quality Forum (NQF), Office of the National Coordinator for Health Information Technology (ONC), Quality Reporting Document Architecture (QRDA).

Correspondence: Elham Hatef, MD, MPH; Center for Population Health IT, Department of Health Policy and Management, Johns Hopkins Bloomberg School of Public Health, 624 N. Broadway, Room 501, Baltimore, 
Maryland 21205, 443-287- 2284, ehatef1@jhu.edu

DOI: $10.5210 /$ ojphi.v9i3.8129

Copyright @2017 the author(s)

This is an Open Access article. Authors own copyright of their articles appearing in the Online Journal of Public Health Informatics. Readers may copy articles without permission of the copyright owner(s), as long as the author and OJPHI are acknowledged in the copy and the copy is used for educational, not-for-profit purposes.

\section{Introduction}

Over the recent period, the Maryland Department of Health (MDH) has been preparing for alignment of its population health initiatives with the next phase of the Maryland Hospital AllPayer Model [1,2]. Maryland's federally-supported All-Payer Model [2] is a unique demonstration project that allocates hospitals with a fixed global budget from all payers, both public and private, to provide care for every state resident. The State considers the alignment of all stakeholders critical to improving the health of Marylanders especially in communities with restricted resources and poor health outcomes. Essential to this process is the development and implementation of indicators for monitoring the health of the residents and holding the hospital systems, now under the Centers for Medicare and Medicaid Services (CMS) demonstration project "microscope", accountable for achieving those end-points.

To move towards this goal, we identified and performed initial preparatory work on a starter set of measures that address broad indicators of community level health such as chronic disease, social risk factors associated with illness, and potentially inappropriate hospital utilization. Similar to a handful of other leading states, Maryland's development and wide scale implementation of electronic health records (EHRs) [3] and a universal state-wide health information exchange (HIE) which is moving towards health data interoperability [4], provides an unprecedented opportunity to assess the community-level population health on an automated basis. This growing community-wide real-time digital health information infrastructure complements the assessments generated from ad-hoc surveys, vital records, and health plan claims data.

A proposed population health framework and set of measures in Maryland aligned with the AllPayer Model is described in a separate paper [5]. This article explores the potential role of EHRs and other health IT resources as the basis of these comprehensive statewide population health measures at the neighborhood level and also offers a technical assessment of the Maryland health IT platform's readiness. We believe it will serve as a model for other US states or regions that are, or soon will be, in similar situations.

Following, we describe a digital measurement progression plan and data assessment for four selected population health measures at various geographic levels. We then provide recommendations for improving digital data collection and management in support of those metrics as part of the universal monitoring system over time. In addition, we briefly describe the current status of EHR data collected by the statewide Maryland HIE (a.k.a., Chesapeake Regional Information System for our Patients, or CRISP) [6] and provide recommendations for increasing the population level coverage of the reported metrics. We offer this description and assessment as a potential guide to health care and public health agencies across the nation and globe. 


\section{Maryland’s Population Health Progression Plan and Data Assessment}

\section{The Progression Plan}

Maryland's proposed population health measurement plan over a ten-year window includes four initial community-level measurement domains: body mass index (BMI) screening and follow up (f/u), screening for high blood pressure (BP) and f/u, smoking status and cessation assistance, and monitoring of falls-related injuries.

The proposed population health measures are considered in reference to Maryland State Health Improvement Process (SHIP) [7], which is aligned with the Healthy People 2020 objectives established by the US Department of Health and Human Services [7]. While the Maryland SHIP defines the population health focus areas for the state, it is limited to long term multiple-year goals for population health and is mainly based on periodic survey data at the state, county or other large geographic levels.

The proposed digital population health measurement progression plan (Table 1) considers the underlying SHIP limitations and the availability, accessibility, and quality of the new statewide electronic data. The novel digital data sources rely less on survey and billing data, and instead, attempt to utilize EHR data that are individual-level, geographically granular, and real-time.

For instance, collecting data on BMI screening based on clinician-patient interaction (or lack thereof), helps to address the long-term state goal of detecting "adults who are a healthy weight" and "children and adolescents who are obese". It also supports the longer-term idea of developing a state-wide surveillance system to assess obesity across the state with individual level data. This EHR-derived measure is based on the National Quality Forum (NQF) measure \# 0421 [8] and CMS measure \# 69 [9]. The NQF measure is defined for those 18 years and older. We expanded the measure to include those younger than 18. The combination of this measure with the existing survey-based BMI measure captured through Maryland's SHIP provides the potential to extract BMI metrics across all patient age groups and locations on a much shorter interval.

\section{Assessment of the Current and Near Time Available Non-Clinical Data for Population Health Measurements}

Table 1 outlines existing and near time available data sources for each of the proposed measures, changes in data availability and completeness over time, and the geographic/ individual granularity on which each measure can be assessed in Maryland. 
A State-wide Health IT Infrastructure for Population Health: Building a Community-wide Electronic Platform for Maryland's All-Payer Global Budget

Table 1. Proposed Maryland Digital Measurement Progression Plan and Data Assessment for Four Selected Population Health Measures over Time and at Various Geographic Levels

\begin{tabular}{|c|c|c|c|c|c|c|c|c|c|}
\hline $\begin{array}{l}\text { Measurement Type Based } \\
\text { on Available Data } \rightarrow\end{array}$ & \multicolumn{6}{|c|}{ Process and Output } & \multicolumn{3}{|c|}{ Outcome/ Impact } \\
\hline $\begin{array}{l}\text { Time Frame for Collecting } \\
\text { Proposed Measures } \rightarrow\end{array}$ & \multicolumn{3}{|c|}{ Short Term (Current) } & \multicolumn{3}{|c|}{ Near Term (2 years) } & \multirow{3}{*}{\multicolumn{2}{|c|}{$\begin{array}{l}\text { Mid to Long Term } \\
\text { (3 to } 5 \text { years) }\end{array}$}} & \multirow[t]{4}{*}{$\begin{array}{l}\text { Longer Term } \\
\text { (8 to } 10 \text { years) }\end{array}$} \\
\hline $\begin{array}{l}\text { Available Geographic Level } \\
\text { over Time (Based on Available } \\
\text { Data Source) } \rightarrow\end{array}$ & $\begin{array}{l}\text { Zip code/ } \\
\text { Track }\end{array}$ & County & State & \multicolumn{2}{|c|}{ Individual } & $\begin{array}{l}\text { Zip code/ } \\
\text { Track }\end{array}$ & & & \\
\hline $\begin{array}{l}\text { Available Data Sources over } \\
\text { Time } \rightarrow\end{array}$ & \multirow[t]{2}{*}{ HSCRC } & \multirow[t]{2}{*}{ BRFSS $^{* *}$} & \multirow[t]{2}{*}{ Medicaid } & \multirow[t]{2}{*}{$\begin{array}{l}\text { EHR } \\
\text { (documented } \\
\text { measures by } \\
\text { providers) }\end{array}$} & \multirow[t]{2}{*}{$\begin{array}{l}\text { CRISP } \\
\text { (transmitted and } \\
\text { stored data from } \\
\text { providers to } \\
\text { CRISP) }\end{array}$} & \multirow[t]{2}{*}{ MCDB } & & & \\
\hline $\begin{array}{l}\text { Measurement Domains } \downarrow \\
\text { and Change in Measurement } \\
\text { Domains Over Time } \rightarrow\end{array}$ & & & & & & & \multicolumn{2}{|c|}{ SHIP Categories } & \\
\hline \multirow[b]{2}{*}{$\begin{array}{l}\text { BMI screening and follow-up for } \\
\text { community/ population (NQF } \\
\text { measure \# } 0421 \text { and CMS measure \# } \\
69 \text { ) }\end{array}$} & & \multirow{2}{*}{$\begin{array}{l}\text { BMI score based } \\
\text { on self-reported } \\
\text { weight and } \\
\text { height of a } \\
\text { representative } \\
\text { sample (12,369 } \\
\text { people) for the } \\
\text { state of Maryland }\end{array}$} & & \multirow{2}{*}{$\begin{array}{l}\text { BMI score based } \\
\text { on measured } \\
\text { height and weight } \\
\text { by providers in the } \\
\text { clinic }\end{array}$} & \multirow{2}{*}{$\begin{array}{l}\text { BMI score based } \\
\text { on data found in a } \\
\text { C-CDA. } \\
\text { Intervention and } \\
\text { procedure orders } \\
\text { within a C-CDA } \\
\text { are not available, } \\
\text { which is necessary } \\
\text { to calculate } \\
\text { follow-up visits }\end{array}$} & & Healthy Living & $\begin{array}{l}\text { Adults who are } \\
\text { a healthy } \\
\text { weight }\end{array}$ & \multirow[t]{2}{*}{$\begin{array}{l}\text { Obesity surveillance in } \\
\text { a specific catchment } \\
\text { area using EHR data }\end{array}$} \\
\hline & & & & & & & & $\begin{array}{l}\text { Children and } \\
\text { adolescents } \\
\text { who are obese }\end{array}$ & \\
\hline $\begin{array}{l}\text { Screening for high BP and follow-up } \\
\text { for community/population (CMS } \\
\text { measure \# 22v5) }\end{array}$ & & & & $\begin{array}{l}\text { Screening for high } \\
\text { BP and follow-up } \\
\text { for a } \\
\text { community/popula } \\
\text { tion (with specific } \\
\text { BP) }\end{array}$ & $\begin{array}{l}\text { BP measure based } \\
\text { on data found in } \\
\text { C-CDA. There is } \\
\text { partial coverage } \\
\text { for data needed to } \\
\text { calculate follow- } \\
\text { up visits }\end{array}$ & $\begin{array}{l}\text { Claims data on } \\
\text { screening for high } \\
\text { BP and follow-up } \\
\text { visit }\end{array}$ & $\begin{array}{l}\text { Quality } \\
\text { Preventive Care }\end{array}$ & $\begin{array}{l}\text { Emergency } \\
\text { department visit } \\
\text { rate due to } \\
\text { hypertension }\end{array}$ & $\begin{array}{l}\text { BP surveillance in a } \\
\text { specific catchment } \\
\text { area with application } \\
\text { of BP measurements } \\
\text { through EHR }\end{array}$ \\
\hline
\end{tabular}


A State-wide Health IT Infrastructure for Population Health: Building a Community-wide Electronic Platform for Maryland's All-Payer Global Budget

\begin{tabular}{|c|c|c|c|c|c|c|c|c|c|}
\hline $\begin{array}{l}\text { Current adult smoking within } \\
\text { population }\end{array}$ & & $\begin{array}{l}\text { Based on the } \\
\text { BRFSS } \\
\text { questionnaire } \\
\text { asking current } \\
\text { smoking habits } \\
\text { among adults of } \\
\text { a representative } \\
\text { sample (12,369 } \\
\text { people) for the } \\
\text { state of Maryland }\end{array}$ & $\begin{array}{l}\text { Claims data on } \\
\text { smoking } \\
\text { medical } \\
\text { assistance }\end{array}$ & $\begin{array}{l}\text { Individual data on } \\
\text { smoking/tobacco } \\
\text { use cessation, and } \\
\text { medical assistance }\end{array}$ & $\begin{array}{l}\text { Most data } \\
\text { elements needed } \\
\text { to calculate } \\
\text { smoking cessation } \\
\text { will be found in a } \\
\text { C-CDA }\end{array}$ & $\begin{array}{l}\text { Claims data on } \\
\text { smoking medical } \\
\text { assistance }\end{array}$ & Healthy Living & $\begin{array}{l}\text { Adults who } \\
\text { currently smoke }\end{array}$ & $\begin{array}{l}\text { Application of } \\
\text { smoking status } \\
\text { measurement through } \\
\text { EHR for surveillance } \\
\text { of smoking trends in a } \\
\text { specific catchment } \\
\text { area }\end{array}$ \\
\hline Falls; Fall-related injury rate & $\begin{array}{l}\text { Number of falls } \\
\text { resulted in an ED } \\
\text { visit or } \\
\text { hospitalization in } \\
\text { a zip code } \\
\text { including } \\
\text { physician } \\
\text { services } \\
\text { categorized as an } \\
\text { outpatient data or } \\
\text { emergency room } \\
\text { visit }\end{array}$ & $\begin{array}{l}\text { History of falls; a } \\
\text { representative } \\
\text { sample (12,369 } \\
\text { people) for the } \\
\text { state of Maryland }\end{array}$ & $\begin{array}{l}\text { Claims data on } \\
\text { falls related ED } \\
\text { visit and } \\
\text { hospitalization }\end{array}$ & $\begin{array}{l}\text { Individual data on } \\
\text { falls related visit } \\
\text { in ED or inpatient }\end{array}$ & $\begin{array}{l}\text { Data on falls } \\
\text { related visit in ED } \\
\text { or inpatient }\end{array}$ & $\begin{array}{l}\text { Claims data on ED } \\
\text { visit and } \\
\text { hospitalization }\end{array}$ & $\begin{array}{l}\text { Healthy } \\
\text { Communities }\end{array}$ & $\begin{array}{l}\text { Fall-related } \\
\text { death rate }\end{array}$ & $\begin{array}{l}\text { Falls surveillance } \\
\text { including repeated } \\
\text { falls among } \\
\text { individuals in a } \\
\text { specific catchment } \\
\text { area using EHR data }\end{array}$ \\
\hline
\end{tabular}

* Note that the full measurement plan also includes cost and patient experience measures.

** Currently in-use data. Other data sources are available in different time frames which potentially could provide population health assessment.

BMI: Body Mass Index, BP: Blood Pressure, BRFSS: Behavioral Risk Factor Surveillance System, C-CDA: Consolidated-Clinical Document Architecture, CMS: Center for Medicare and Medicaid Services, CRISP: Chesapeake Regional Information System for our Patients, ED: Emergency Department, EHR: Electronic Health Record, HSCRC: Health Services Cost Review Commission, MCDB: Maryland Medical Care Data Base, NQF: National Quality Forum, SHIP: State Health Improvement Process. 
Currently in-use data sources: self-reported BMIs, smoking habits, and history of falls are collected through the CDC- designed Behavioral Risk Factor Surveillance System (BRFSS) survey of 12,369 Maryland residents on a county level. Indeed, in Maryland (and most other states), the BRFSS is the major source of data for the SHIP and currently reported population health measures [7].

Current and near-time available data sources: There are other sources of available data which could address population health measurements of interest. For instance, Maryland Medical Care Data Base (MCDB) includes enrollment, provider, and claims data for Maryland residents enrolled in private insurance. This database provides claims on screening for high BP and f/u visits, smoking cessation assistance, and falls related emergency department (ED) visit and hospitalization [10].

In addition, Maryland's Health Services Cost Review Commission (HSCRC) database [11] provides administrative and billing information for all regulated hospital care under the AllPayer Model. The HSCRC's Inpatient dataset contains discharge medical record abstracts including all diagnoses and billable services provided for each inpatient admission. The HSCRC's outpatient data contains medical abstracts and billing data on all emergency department and other outpatient surgeries, clinic visits, and referred outpatient ancillary utilization occurred in a hospital setting. Though not currently applied for the purpose of population health measurement, these datasets could provide the number of falls resulted in an ED visit or hospitalization in a zip code or at the census block level, or even individual level.

Maryland has not yet required the facilitation of the technical infrastructure and legal issues related to accessing these data sources for the purpose of the population health assessment and improvement.

\section{Assessment of the Current and Near Time Available Clinical Data (EHR) for Population Health Measurements}

Currently available data sources: Maryland has a comprehensive health-related digital data infrastructure [12]. Presently, CRISP, the state HIE, is able to partially calculate the population health measures for all hospitals using the Clinical Quality Measure (CQM) [13] Aligned Population Health Reporting Tool (CAliPHR tool), "a tool designed to give eligible providers the ability to meet the clinical quality measurement requirements of federal and state incentive, as well as value-based programs”. [14]

Most health delivery systems in Maryland have been compliant with CMS Meaningful Use [15] (now part of The Medicare Access and CHIP Reauthorization Act (MACRA); the EHR incentive payment program) [16] and are recording vitals data including BMI, BP, and smoking status for most visits (more than 75\% of their visits) and falls-related injuries for many visits (more than $50 \%$ of their visits); however, as of 2016 CRISP receives EHR data from the health delivery systems on BMI, BP, and smoking status for only about $25 \%$ of patients and on falls related injuries for $<10 \%$ of patients. This substantial drop between what is collected at the health delivery system and what is actually being transmitted to CRISP is a result of the vital data not being always captured in the "Consolidated Clinical Document Architecture" (C-CDA) documents [17] that are sent to CRISP from the health delivery systems. As of 2017 the C-CDA 
[17] serves as the base standard for generating electronic clinical documents and is used by CRISP for receiving and storing EHR data from eligible providers across the health delivery systems in Maryland.

Maryland is still required to address the legal issues to accessing the currently available and transmitted EHR data to CRISP for the purpose of population health assessment and improvement.

Near-time available data sources: The 2015 Edition Health IT Certification Criteria (2015 Edition) from the Office of the National Coordinator for Health Information Technology (ONC) aims "to facilitate greater interoperability for several clinical health information purposes and enables health information exchange through new and enhanced certification criteria, standards, and implementation specifications”. [18]

The roll out of the 2015 Edition Health IT Certification Criteria [18] by different EHR vendors should potentially result in an increased number of providers and practice sites sending their EHR data in C-CDA documents to HIEs across the country. In Maryland, an anticipated 2,000 providers send their EHR data in C-CDA's documents to CRISP. Approximately 80 of these practice sites integrated with the CAliPHR tool [14], will have the ability to meet the clinical quality measurement requirements of federal and state incentive, and could partially calculate each proposed population health measure by the end of 2017.

These upgraded EHRs will be capable of exporting Quality Reporting Document Architecture (QRDA) Category 1 files [19] which are necessary to calculate the EHR-based proposed measures. The QRDA Category 1 files are the ONC's recommended standard document format for the exchange of electronic clinical quality measures (eCQMs) data which are reinforced by CMS [19].

By 2018 all providers participating in the EHR Incentive Program or the Quality Payment Program will be required to have adopted 2015 Edition Certification [18]. CRISP anticipates having 3,500 providers sending their EHR data in C-CDA documents and approximately 130 of these practice sites will be integrated with the CAliPHR tool. This advancement provides an opportunity for the state to move toward the application of EHR data as the main data source for population health assessment and improvement. Maryland will need to address the legal issues related to this new application of the available data.

\section{Conclusions and Potential Strategy to Improve Electronic Data Quality for Population Health Measurements}

Optimal interoperability and adequate data exchange infrastructure are vital to operationalizing population health interventions and measurements [20]. Capturing and collecting data for the population health measures require special efforts from multiple stakeholders to expand the data exchange infrastructure and data interoperability among health providers [21]. As the market continues to mature and new interoperability standards become available, there may be alternative data collection methods employed for each population health measure, on a case by case basis. 
In this report, we described Maryland's incremental approach by selecting a number of initial population health measures and focusing on available data from providers and practices while planning for an expansion of new data sources. This allows public health agencies to extract useful population health data from day one, while gradually making progress towards the overall goal of conducting more comprehensive and outcome-based measurements. This strategy will be impacted by market/industry factors, data availability, funding, and measure authoring cycles. As a result, the timelines and milestones will be subject to necessary change and must remain flexible.

Future steps for statewide and/or local health departments interested in utilizing health IT for population health measurement, may include various challenges and opportunities with different timelines. Following, we offer some recommendations to help guide this process:

- In the next 3-5 years, states interested in developing a population health measurement approach will need to continue to monitor CMS programs that require CQM reporting such as Merit-Based Incentive Payment Systems (MIPS), Alternative Payment Models (APM), and the Hospital Inpatient Quality Reporting program [16] and align state required measures as much as possible. This will be particularly important with eCQMs [22] as it may be difficult to require EHR vendors to calculate state-specific eCQMs [23].

- States should consider additional steps to support data collection at the state level and continue to support data gathering from their HIE. States may consider (1) mandating their providers to submit QRDA data on the proposed measures to a state organization; (2) incentivize voluntary submission of other key population health measures; and/or, (3) contract with an organization to provide practice level support to providers to collect and report population health measures via QRDA.

- States may want to consider incorporating and aggregating multi payer claims data (commercial, Medicaid and Medicare) to selected population health measures such as BMI and BP f/u intervention (not the actual BMI or BP score) and to measure other population health measures such as falls risk intervention activities namely education and awareness.

- In the longer term (8 to 10 years), States should take additional steps to support coalescing interoperable data at the state level by continuously gathering data from their HIEs.

- States should work with stakeholders to monitor the evaluation of emerging standards, such as "fast healthcare interoperability resources" (FHIR); a standard for exchanging healthcare information electronically) [24], and to determine if additional data collection/submission mechanisms should be incorporated in their population health measurement approach. They should continue to support their ongoing CMS-motivated APM transformation efforts.

- States should consider incorporation of home health, self-monitoring, and/or data gathering on population health measures such as self-reported BMI and BP information by smart watch, personal home-based tablets, and telehealth activities. In addition, they should consider recording of tobacco use status outside the standard clinical settings. They may also consider measurements of 
patient engagement strategies, incentives and deterrents, not just status reporting of tobacco.

- States should address the various privacy regulations and data governance provisions with regard to access to individual level data.

In this paper, we presented a population health assessment model for communities across the US on the road to interoperable EHRs that one day will offer real-time data collection on almost all residents. We introduced the potential expansion of health IT capacity as a key tool for improving population health across the country which for the first time in the history of US health system will soon be feasible on a wide scale. But for this to happen a special coordinated effort from multiple stakeholders will be required to expand the interoperable digital infrastructure along the lines we lay out in this article at the community level.

\section{Financial Disclosure}

This project was supported through a State Innovation Model Round Two design grant from the Centers for Medicare and Medicaid Services' (CMS) Innovation Center awarded to the Maryland Department of Health (MDH). Maryland's Health Information Exchange (a.k.a., Chesapeake Regional Information System for our Patients, or CRISP) and the Center for Population Health IT at the Johns Hopkins Bloomberg School of Public Health have provided technical expertise as subcontractors. Any recommendations put forth in this article are the views of the authors and do not necessarily represent the views of MDH or CMS.

\section{Competing Interests}

No Competing Interests.

\section{References}

1. Maryland Population Health Improvement Plan. Planning for population health improvement. Available at:

https://mmcp.dhmh.maryland.gov/Documents/SIM\%20Round\%20Two/Appendix\%20C_Ma ryland\%20Population\%20Health\%20Improvement\%20Plan_for\%20website.pdf

2. Maryland all-payer model. Available at: https://Innovation.cms.gov/initiatives/maryland-allpayer-model/

3. Adoption of electronic health record systems among U.S. non-federal acute care hospitals: 2008-2015. Available at: https://Dashboard.healthit.gov/evaluations/data-briefs/non-federalacute-care-hospital-ehr-adoption-2008-2015.php

4. Connecting health and care for the nation: A 10-year vision to achieve an interoperable health IT infrastructure. Available at:

https://Www.healthit.gov/sites/default/files/ONC10yearInteroperabilityConceptPaper.pdf

5. Hatef E, Lasser EC, Kharrazi H, Perman C, Montgomery R, et al. 2017. A Population Health Measurement Framework: Evidence-Based metrics for assessing community-level 
population health in the global budget context. Popul Health Manag. In press. PubMed https://doi.org/10.1089/pop.2017.0112

6. Chesapeake regional information system for our patients. Available at: https://Crisphealth.org

7. Maryland state health improvement process. Available at: http://Dhmh.maryland.gov/ship/pages/home.aspx

8. NQF \#0421 Preventive Care and Screening: Body Mass Index (BMI) Screening and FollowUp. Available at:

https://www.qualityforum.org/WorkArea/linkit.aspx?LinkIdentifier=id\&ItemID=71112

9. The Centers for Medicare and Medicaid services and the Office of the National Coordinator for Health Information Technology (ONC). U.S. department of health and human services. Preventive care and screening: Body mass index (BMI) screening and follow-up plan. Available at: https://ecqi.healthit.gov/ecqm/measures/cms069v4

10. The Maryland Medical Care Data Base (MCDB). Available at: http://mhcc.maryland.gov/mhcc/pages/apcd/apcd_mcdb/apcd_mcdb.aspx

11. The Maryland Health Services Cost Review Commission (HSCRC) Available at. http://hscrc.maryland.gov/Pages/default.aspx.

12. Kharrazi H, Horrocks D, Weiner JP. Use of HIEs for value-based care delivery: A case study of Maryland's HIE. In Dixon B (Ed.) Health Information Exchange: Navigating and Managing a Network of Health Information Systems (Ed. Dixon). 2016; 313-332. AP Elsevier. ISBN: 978-0-12-803135-3

13. The Centers for Medicare \& Medicaid Services. Clinical quality measures basics. Available at: https://Www.cms.gov/regulations-andguidance/legislation/ehrincentiveprograms/clinicalqualitymeasures.html

14. Chesapeake regional information system for our patients (CRISP). CQM aligned population health reporting (CAliPHR) tool. 19]; Available at:

https://Www.crisphealth.org/services/cqm-aligned-population-health-reporting-caliphr-tool/

15. The Center for Medicare and Medicaid services. Electronic health record (EHR) incentive programs. Available at: https://www.cms.gov/regulations-andguidance/legislation/EHRIncentivePrograms/index.html?redirect=/ehrincentiveprograms

16. The Centers for Medicare and Medicaid Services. MACRA: MIPS and APMS. Available at: https://Www.cms.gov/medicare/quality-initiatives-patient-assessment-instruments/valuebased-programs/MACRA-MIPS-and-APMs/MACRA-MIPS-and-APMs.html

17. Health IT. gov. consolidated clinical document architecture (C-CDA). Available at: https://www.healthit.gov/policy-researchers-implementers/consolidated-cda-overview 
18. The Office of the National Coordinator for Health Information Technology (ONC) Health IT Certification Program. Standards and certification regulations. Available at: https://www.healthit.gov/policy-researchers-implementers/standards-and-certificationregulations

19. The Centers for Medicare and Medicaid Services and the Office of the National Coordinator for Health Information Technology (ONC). U.S. Department of Health and Human Services. What's the quality reporting document architecture (QRDA)? Available at: https://Ecqi.healthit.gov/qrda

20. Kharrazi H, Lasser EC, Yasnoff WA, et al. 2017. A proposed national research and development agenda for population health informatics: Summary recommendations from a national expert workshop. J Am Med Inform Assoc. 24(1), 2-12. https://doi.org/10.1093/jamia/ocv210

21. Kharrazi H, Weiner JP. 2014. IT-enabled community health interventions: Challenges, opportunities, and future directions [eGEMs]. Generating Evidence \& Methods to Improve Patient Outcomes. 2(3), 1117. PubMed

22. The Centers for Medicare and Medicaid Services. Electronic clinical quality measures (eCQM) basics. Available at: https://Www.cms.gov/regulations-andguidance/legislation/EHRIncentivePrograms/eCQM_Library.html

23. The Centers for Medicare and Medicaid Services. The Medicare Access \& Chip Reauthorization Act of 2015. Quality Payment Program. All-payer combination Option. Available at: https://Www.cms.gov/medicare/quality-initiatives-patient-assessmentinstruments/value-based-programs/MACRA-MIPS-and-APMs/quality-payment-programall-payer-overview.pdf

24. Fast healthcare interoperability resources. Available at: https://Www.hl7.org/fhir/overview.html 